\title{
200 years of surgery at the General Hospital, Singapore
}

\author{
Joshua Quan Chen Ooi ${ }^{1}$, London Lucien Peng Jin $\underline{\text { Ooi }}{ }^{2}{ }^{M D}$
}

Western medicine in Singapore began with Sir Stamford Raffles' arrival on 28 January 1819 with a sub-assistant surgeon, Dr Thomas Prendergast, providing medical care for the expedition. ${ }^{1}$ The first official surgeon, Dr William Montgomerie, arrived in May that year with the 2nd Battalion, 20th Regiment, Bengal Native Infantry and he also attended to the surgical needs of Singapore's leaders then. ${ }^{2}$

In 1821, a medical facility was set up in the cantonment near Bras Basah Road, and named the "General Hospital” (GH). ${ }^{3}$ This makeshift shed collapsed and was rebuilt a year later. With crumbling infrastructure, the GH was again rebuilt in 1827 and renamed the "Civil Hospital" or "Singapore Infirmary". ${ }^{3}$

The hospital moved to Pearl's Hill in 1844 as the "Seaman's Hospital", and thereafter to Kandang Kerbau district in 1856 when it resumed its original name, and incorporated the "Pauper's Hospital" that became Tan Tock Seng Hospital (TTSH). ${ }^{3-5}$

A cholera outbreak in 1873 led to a temporary move to Sepoy Lines. As a better, more central site, this became the final location with the 7th GH built in 1882 (Fig. 1). ${ }^{3,4}$ In those days, few surgeries were performed, mainly for trauma and infections, ${ }^{6}$ with 58 operations recorded in 1884, 121 in 1885, increasing to 200 in 1903, and 226 in $1904 .{ }^{1}$ The surgical staff comprised a chief surgeon, who had no formal postgraduate surgical qualifications, ${ }^{6}$ and an assistant, operating through two 30-bed surgical wards.

In 1905, the Straits Settlements and Federated Malay States Government Medical School became the first medical school in the country. ${ }^{7}$ Dr J Gray, resident medical officer (MO) at TTSH, which was the only other hospital that provided surgical services then, applied for the post of Lecturer in Surgery. However, Dr ED Whittle, MO in Penang, Malaya since 1909, was offered the position, with instructions to sit for his Fellowship examinations when he was back in England. Dr Gray held the post temporarily in 1912 until Dr Whittle arrived in 1913 to assume concurrent roles of Lecturer

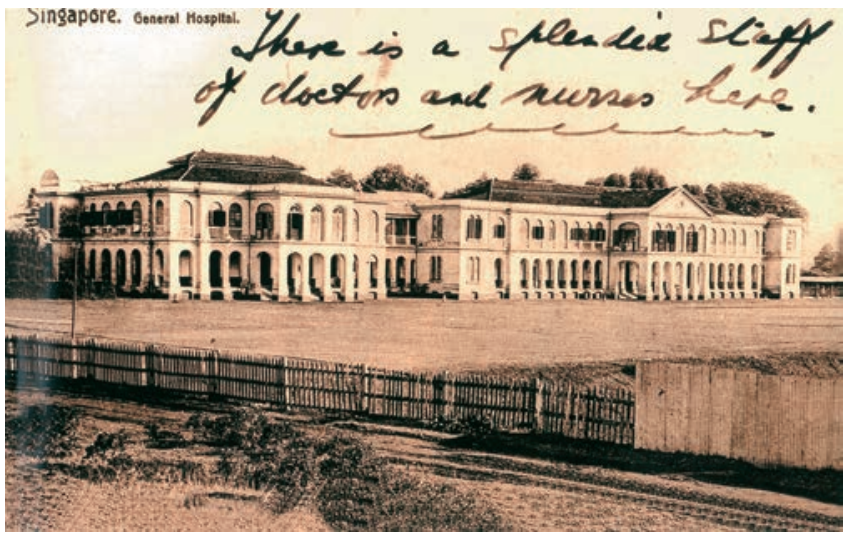

Fig. 1. The General Hospital at Sepoy Lines in 1882 as seen from a postcard. Credit: SGH Museum. Used with permission from Singapore General Hospital.

in Surgery and Surgeon (Specialist) at the GH, and Visiting Surgeon, TTSH, ${ }^{8}$ as the first surgeon with postgraduate qualifications. ${ }^{6}$

The new GH at Sepoy Lines had wards for European, Eurasian and "better-class" native patients in 3 classes. In 1914, 261 operations were done in this cohort, compared to 861 in Native wards for the general population. ${ }^{8}$ The following year, Dr Whittle died in the mutiny of the Indian sepoys ${ }^{8}$ and was replaced by Dr CJ Smith, surgeon at TTSH, as Senior Surgeon (Singapore). ${ }^{4,5,8}$

The General Medical Council, United Kingdom (GMC) conferred recognition of the Licentiate in Medicine and Surgery (LMS) diploma of the medical school in 1916. ${ }^{9}$ However, in 1919, GMC citations for shortfalls in teaching standards and assessments led to the creation of formal academic posts including that of Professor of Surgery. This was filled by Mr Kenneth Black in 1922, who also established the ophthalmic service in the GH. ${ }^{10}$

With overcrowding and better infrastructure needed, a new GH was officially opened by Sir Lawrence Gunn, Governor of the Straits Settlements, on 29 March 1926 and named "Singapore General Hospital"

\footnotetext{
${ }^{1}$ University of New South Wales, Australia

${ }^{2}$ Department of Hepatopancreatobiliary and Transplant Surgery, Singapore General Hospital, Singapore

Correspondence: Prof London Lucien Ooi, Department of Hepatopancreatobiliary and Transplant Surgery, Singapore General Hospital, 20 College Road, Academia, Singapore 169856.

Email: london.lucien.ooi.p.j@singhealth.com.sg
} 
(SGH) (Fig. 2). ${ }^{4}$ The Upper block had 1st/2nd class male and 1st class female wards, the Middle 2nd/3rd class female and children's wards, and the Lower 3rd class male wards (Fig. 3). ${ }^{4}$ With 800 beds in total, there was an increase of surgical beds to 144 that allowed an average of 1,100 major and 1,290 minor operations a year by the 1930s. ${ }^{6}$ The GH also shifted from treating mainly Europeans and the military/sailors, to also providing care to the larger population. ${ }^{4}$

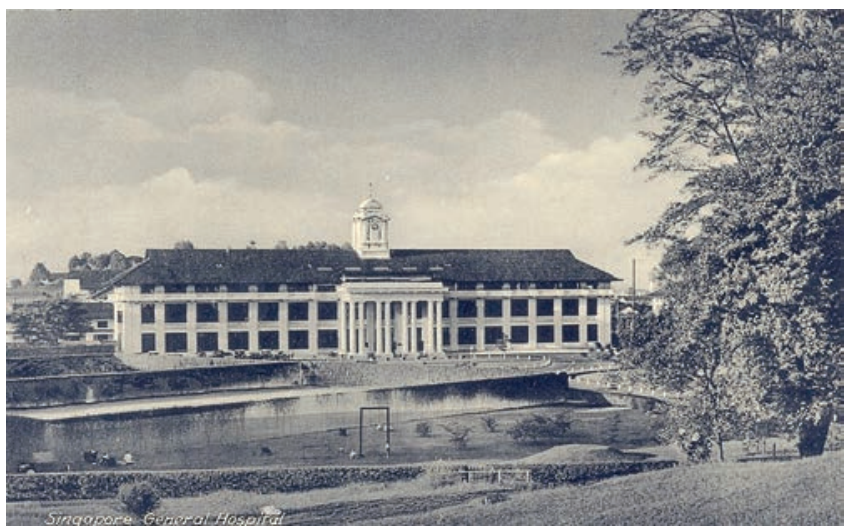

Fig. 2. The Upper Block at the "new" Singapore General Hospital at Sepoy Lines in 1926 with a golf course in the foreground. This was later renamed Bowyer block after the Second World War. The clock tower remains today as a central landmark on SGH Campus.

Credit: SGH Museum. Used with permission from Singapore General Hospital.

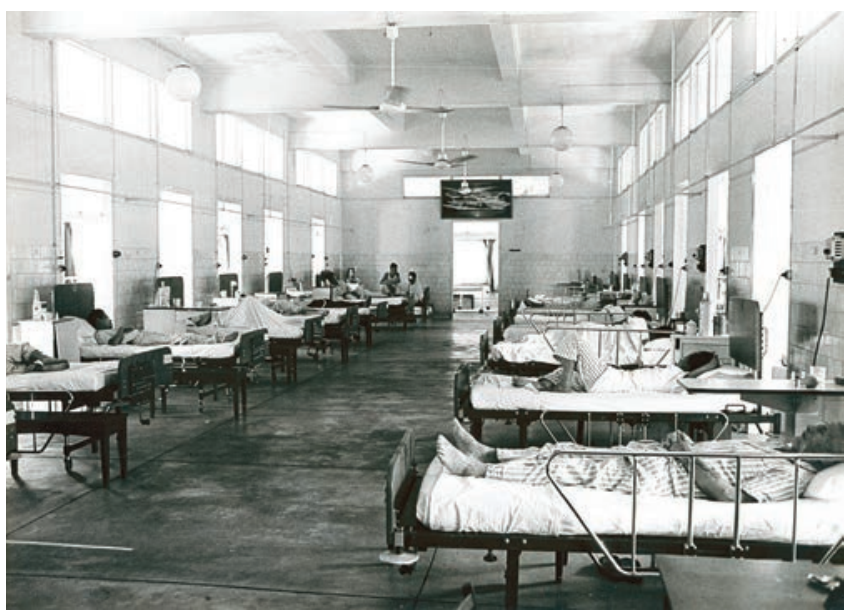

Fig. 3. A typical open ward (male) in the old Singapore General Hospital as seen in the 1970s.

Credit: SGH Museum. Used with permission from Singapore General Hospital.

By this time, SGH had two key surgical appointments-Mr CJ Smith (1914-1934), the Senior Surgeon (Singapore) responsible for surgical care, and Mr K Black (1922-1936), Professor of Surgery responsible for surgical education and training. A new position, Professor of Clinical Surgery, was filled by Mr BM Johns in 1928 who also introduced ear, nose and throat (ENT) services into SGH. ${ }^{10}$

The number of surgeries increased progressively. In 1934, records showed 3,758 operations with additional 344 ophthalmic, 641 ENT and 300 gynaecological procedures, ${ }^{10}$ which later increased to 6,000 operations per year by $1940 .^{6}$

The war years (1942-1945) saw SGH become the main surgical centre for Southeast Asia, treating casualties of the Japanese Armed Forces. ${ }^{3}$

When war ended, SGH's Upper, Middle and Lower blocks were renamed Bowyer, Stanley and Norris blocks, respectively, in honour of 3 SGH doctors who died during the war. ${ }^{3}$ A GMC review in the post-war recovery period suggested establishment of a system of surgical and medical units, which did not exist prior to $1947.3,4$ Surgical services were set up as 3 distinct units-Surgery "A" headed by Professor JK Munro, Surgery "B" headed by Mr BM Johns, and Surgery "D" headed by Professor EC Mekie, and a separate ophthalmic unit under Dr AD Williamson. ${ }^{3,5}$

The early 1950s was also a period of progressive specialisation.

In 1951, the Chair of Clinical Surgery was converted to the Chair of Orthopaedics, ${ }^{5}$ and with the appointment of Mr JAP Cameron in 1952, Unit "D" provided orthopaedic services. A separate government Orthopaedics Unit "O" was set up in 1956 by $\mathrm{Mr}$ DWC Gawne., ${ }^{4,5,11}$ Later, in 1959, Surgery "D" was renamed Orthopaedic "C", and subsequently University Department of Orthopaedic Surgery in 1972.5,10,11 The country's first Burns Unit was set up in 1959 under the Orthopaedics unit. ${ }^{3}$

ENT services, introduced previously by $\mathrm{Mr} \mathrm{BM}$ Johns, moved to Surgery “B”, becoming a unit in 1951. In 1957, it became the only ENT department in the country until the early 1970s. ${ }^{4,5}$

Ophthalmology, which had started with Mr K Black as a service within Surgery, became a distinct unit with the post-war unit reorganisation, then later a department, ${ }^{5}$ before finally forming the Singapore National Eye Centre in $1992 .^{5}$

In tandem with developments in surgery, there was concomitant developments in anaesthesia. In the early 1920 s, ether or chloroform was the mainstay. It was not until 1930, when anaesthesia became a distinct specialty with doctors dedicated and trained to provide anesthetic services, that a Department of Anaesthesia was created. ${ }^{5}$ 
The year 1970 was a pivotal one for Singapore healthcare and SGH. A Committee on Medical Specialisation, set up by the Ministry of Health, had recommended the development of 5 sub-specialtiesneurosurgery, cardiothoracic surgery (CTS), plastics and reconstructive surgery (PRS), paediatric surgery and a renal dialysis unit. ${ }^{3}$ Plastics surgery services in Surgery and the Burns Unit in Unit C amalgamated into a new Department of PRS in 1972. ${ }^{4,5}$ A paediatric surgery service was also set up before becoming a new Department of Paediatric Surgery in 1981.4,5 Cardiothoracic surgery had earlier been performed in Surgery "A" by Professor Yeoh Ghim Seng (Fig. 4), with the first closed and open heart surgeries in 1959 and 1965, respectively, before CTS was transferred to TTSH. ${ }^{5}$

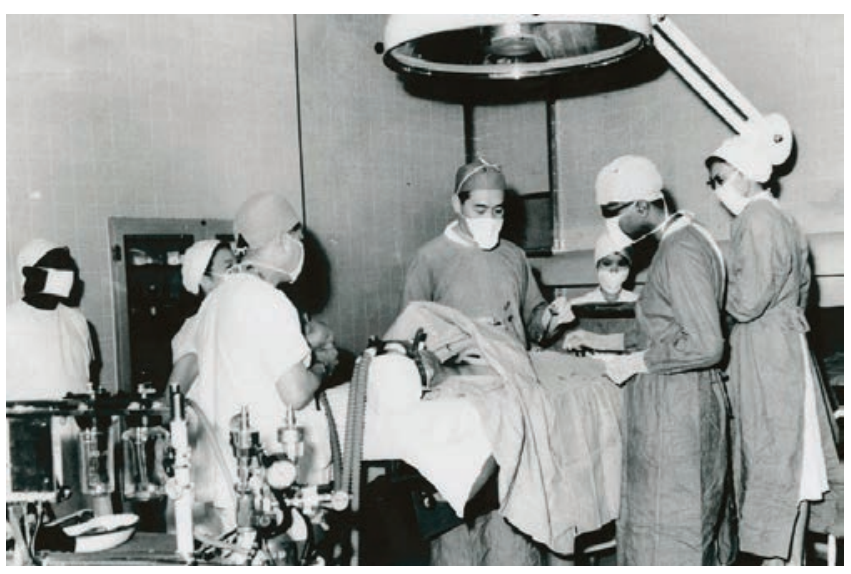

Fig. 4. The operating theatre at the old Singapore General Hospital with the late Professor Yeoh Ghim Seng performing surgery in 1957/8.

Credit: SGH Museum. Used with permission from Singapore General Hospital.

For a brief period in 1968, SGH was renamed Outram Road GH. ${ }^{4}$ On 12 September 1981, then Prime Minister Lee Kuan Yew declared open the new SGH, designed and built to take healthcare standards in Singapore to new heights (Fig. 5). ${ }^{3,4}$ Specialty departments were set up as tertiary referral centres, including the Departments of CTS and Paediatric Surgery in 1981, Hand Surgery in 1985, Obstetrics \& Gynaecology (O\&G) in 1986, Urology in 1988, and Colorectal Surgery and Neurosurgery in $1989 .{ }^{4}$

With these came several "firsts"-living-related renal transplant (1977), toe-to-thumb transplant (1980), total knee replacement (1982), cochlear implant and laparoscopic cholecystectomy (1990). ${ }^{5}$

In 1985, the National University of Singapore moved to Kent Ridge, and the University Department of Orthopaedic Surgery moved as well, followed by

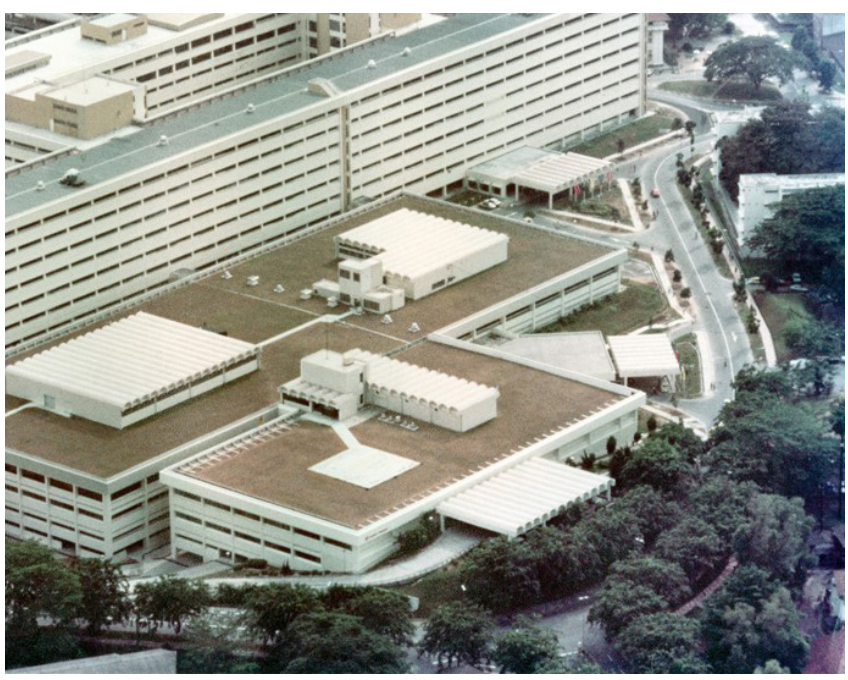

Fig. 5. The "new" Singapore General Hospital opened in 1981.

Credit: SGH Museum. Used with permission from Singapore General Hospital.

Surgery "A" in 1988. Surgery "B" was renamed the Department of Surgery, and later Department of General Surgery. In 1995, Orthopaedic Units “O” and "C" merged into a single department. ${ }^{4}$

Restructuring of SGH came about on 1 April 1989 to enable enhanced management of clinical services. ${ }^{3,4}$ Three Divisions-Medicine, Surgery and Ambulatory \& Clinical Support Services - were formed to oversee the clinical departments. The Division of Surgery, chaired by a senior surgeon, had oversight of the surgical specialty departments, including the Departments of Anaesthesia and O\&G, as well as facilities including the operating theatres, ambulatory surgery centre, sterile supplies and surgical intensive care units.

With changing disease patterns and the evolution of cancers and cardiac diseases as the 2 major causes of mortality in Singapore, SGH set up 2 main disease specialty centres. The Singapore Cancer Centre (SCC) was established in 1993, and saw the creation of a new Department of Surgical Oncology to address surgical needs of cancer patients. The SCC was designated a national centre and became the National Cancer Centre Singapore (NCCS) in 1999. In similar fashion, the Singapore Heart Centre (SHC) was set up in 1994 and became the National Heart Centre Singapore (NHCS) in 1998. ${ }^{12}$

Further organisational change occurred in 2000, with the public healthcare system reorganised into 2 clusters-Singapore Health Services (SingHealth) and National Healthcare Group (NHG) ${ }^{4}$ SGH, together with NCCS and NHCS, became part of SingHealth. ${ }^{12}$ 
The co-location of NCCS and NHCS within SGH campus, and the formation of SingHealth allowed SGH's Division of Surgery to have operational coordination of NCCS' Department of Surgical Oncology and NHCS' Department of CTS, and allowed for continued growth and development of surgical services in SGH campus.

With increasing sub-specialisation, surgery continued to evolve and in 2014, sub-specialty Departments of Hepatopancreatobiliary \& Transplant Surgery, Upper Gastrointestinal Surgery and Vascular Surgery were formed, followed later by Departments for Breast and Head \& Neck Surgery.

The Division of Surgery, which up until 2015 had 16 surgical departments, also continued to evolve. Two new Divisions were spun off: Division of Anaesthesiology and Surgical Intensive Care that absorbed the Departments of Anaesthesia, Pain Management, Hyperbaric Medicine and Surgical Intensive Care; and Division of Musculoskeletal Surgery that oversaw the Departments of Orthopaedics, Hand, and Plastics, Reconstructive \& Aesthetic Surgery. The remaining departments were regrouped under a smaller Division of Surgery and Surgical Oncology.

Today, as the flagship hospital of the public healthcare system in Singapore, SGH performs more than 92,000 inpatient and elective surgical operations a year. ${ }^{13}$ With the announcement on 5 February 2016 by Prime Minister Lee Hsien Loong of the SGH Campus Masterplan, the future of healthcare and of surgery in Singapore's oldest hospital can only get better from the first 200 years. ${ }^{14}$

\section{REFERENCES}

1. Lee YK. A brief introduction to the early history of surgery in Singapore (Part I). Singapore Med J 1997;38:275-7.

2. Buckley CB. An anecdotal history of old times in Singapore 18191867. Vol. 1. Oxford University Press, Singapore, pp 60. In: William Montgomerie arrives in Singapore. HistorySG: An online resource guide, National Library Board. Available at: https://eresources.nlb. gov.sg/history/events/fe2e2d8a-0c84-4925-b92b-d2d6df43a038. Accessed on 1 June 2021.

3. Kwa SB. The Singapore General Hospital: Past, present and future. In: The SGH Lectures: A compilation of the SGH Lectures 1993-2002. Singapore: SGH-PGMI Press; 2004:11-28.

4. Ho LY (Ed). Envisioning a destiny. Singapore: Singapore General Hospital; 2006.

5. Kwa SB, Lim L. The first general hospital: 175th anniversary, 1821-1996. Singapore: Singapore General Hospital; 1996.

6. Nambiar RM. Surgery in Singapore. Arch Surg 2003;138:1397-401.

7. Cheah JS. Approaching 100 years of medical and university education in Singapore. Singapore Med J 2003;44:1-3.

8. Lee YK. A brief introduction to the early history of surgery in Singapore (Part II) Singapore Med J 1997;38:310-2.

9. Ooi QCJ, Mantoo SK, Ooi PJLL. Surgical education and training in Singapore. Indian J Surgery 2021. https://doi.org/10.1007/s12262021-02965-1.

10. Lee YK. A brief introduction to the early history of surgery in Singapore (Part III). Singapore Med J 1997;38:353-5.

11. Satku K, Chacha PB, Low YP. History of the Orthopaedic Specialty in Singapore. Ann Acad Med Singap 2002;31:551-7.

12. SingHealth. Our National Specialty Centres. Available at: https://www.singhealth.com.sg/about-singhealth/newsroom/medsg200/ specialist-centres-history. Accessed on 5 June 2021.

13. Singapore General Hospital. Hospital overview - Singapore General Hospital. Available at: https://www.sgh.com.sg/about-us/ corporate-profile/pages/hospital-overview.aspx. Accessed on 5 June 2021.

14. Singapore General Hospital. Our heritage. Available at: https://www.sgh. com.sg/about-us/corporate-profile/pages/our-heritage.aspx. Accessed on 5 June 2021. 